\title{
Global to Local: An Alternative Approach to Achieve Climate and Energy Goals
}

\author{
Maimuna Kabatesi ${ }^{1}$
}

Published online: 12 July 2021

(c) Society for International Development 2021

\begin{abstract}
Universal energy access currently looks unachievable according to predictions based on current data. This affects Africa most, as has been observed with the effects of COVID-19 leading to a reversal in gains. The world's ambitious climate goals, which also require the achievement of clean cooking show that there is an opportunity for a shift. Channeling climate finance towards decentralized renewable energy and clean cooking can support achievement of universal energy access through more localized action.
\end{abstract}

Keywords Climate finance · Decentralized renewable energy · Energy transition · Low carbon development pathway · Climate change

If there is anything the past year and a half should demonstrate to the global community, it is that now more than ever, our approach to development needs to change. The pandemic has sharply carved out just how unsustainable our current approach to development is. Gains in development indicators slowed down and in many cases there was even regression. Whereas the onset of COVID-19 brought into sharp relief the need for expanded energy access, particularly for marginalized communities and areas, the pandemic itself has actually led to reductions in access to energy. And despite the increased lack of access to energy, COVID-19 responses by governments and development partners did not target increasing energy access. This has led to a situation where we not only risk seeing drastic reductions in development gains due to lack of energy access, but also climate mitigation gains and goals reversed. While there was a short-term reduction in emissions due to the reduction in economic activities, this is not expected to be sustained as it was not a result of purposeful climate actions. The current approaches to improving livelihoods and reducing emissions are not effective. In particular, climate and energy financing

Note: Unless noted otherwise, any reference to or statistic about Africa refers to countries South of the Sahara

Maimuna Kabatesi

mkabatesi@hivos.org

1 Hivos East Africa, Nairobi, Kenya both remain at the large-scale level but do not create the intended change for local communities. There needs to be a shift in what the global community considers effective actions to achieve universal energy access. Climate finance can play a role in this, but climate financing structures themselves must also change.

\section{An Energy Transition?}

For years, the need for the next energy transition has been touted as necessary by stakeholders in energy and development. This energy transition, defined by the International Renewable Energy Agency (IRENA) as a transition from a largely fossil-fuel based global energy system to zero-carbon by the second half of this century, ${ }^{1}$ is required due to the urgent need for response to the climate crisis. Stakeholders such as governments, development partners, multilateral development banks, international agencies, private sector and civil society all highlight the need for a switch to a lowemission pathway. There are also concrete steps taken by these bodies towards a renewable energy transition. The Paris Agreement which came into force in 2020 and requires concrete (albeit non-binding) emission-reduction actions

\footnotetext{
${ }^{1}$ Energy Transition. https://www.irena.org/energytransition\#: :text= The $\% 20$ energy $\% 20$ transition $\% 20$ is $\% 20$ a,second $\% 20$ half $\% 20$ of $\%$ 20this\%20century.\&text=Renewable $\% 20$ energy $\% 20$ and $\% 20$ energy $\%$ 20 efficiency,of $\% 20$ the $\% 20$ required $\% 20$ carbon $\% 20$ reductions.
} 
from countries through Nationally Determined Contributions (NDCs) also underlines the need for action. With reaffirmed commitment from the United States of America, this remains a window of opportunity for the global community, along with the Sustainable Development Goals (SDGs) in particular Goal 7 on energy and Goal 13 on climate action. While most countries are yet to submit their second NDCs, an analysis (Cabré and Youba Sokona 2016) of the first round of African NDCs showed that of 53 submitted NDCs at the time of the research, all but one highlighted renewable energy interventions and/or investment opportunities in the renewable energy sector.

But, while there is a lot of commitment, the fact remains that the renewable energy transition in Africa is not moving as fast as it should. Though renewable energy technology is advancing and costs for the technology are falling, the uptake of or switch to renewable energy still lags behind the ambitious targets set both in African countries and globally. This is attributable to factors such as inadequate policy and regulatory frameworks or lack of political will. However, the most critical missing component is financing. Financing for renewable energy lags behind; and specifically financing for decentralized renewable energy (DRE) which has been touted as the least cost electricity access solution for African countries. ${ }^{2}$ Financing for clean cooking is even more overlooked, with a fairly recent analysis of financial flows for renewable energy finding that financing for clean cooking was actually decreasing ${ }^{3}$ despite the urgency to provide access and eliminate approximately 4 million deaths due to household air pollution annually, mostly of women and children. Without a drastic shift in financing, policy and action from those in power, clean cooking will never receive the attention it deserves.

\section{Funds Must be Responsive to People's Needs}

Various figures and needs have been floated in order to achieve electrification and clean cooking by 2030; targets which we remain woefully behind on. The World Energy Outlook 2017 stated that an additional USD 50b a year would be needed to achieve electrification by 2030 , with $95 \%$ of that additional finance needing to be directed to

\footnotetext{
${ }^{2}$ Energy Access Outlook 2017. https://www.iea.org/reports/energyaccess-outlook-2017.

3 Sustainable Energy for All (SEforALL) and the Climate Policy Initiative (CPI) 2018. Understanding the Landscape - Tracking Finance for Electricity and Clean Cooking Access in High-Impact Countries: 51.
}

Africa. The Energizing Finance 2018 report's analysis finds that an additional USD $32 \mathrm{~b}$ would be needed to achieve clean cooking in what they define as high impact countries, ${ }^{4}$ 14 out of 20 of which are in Africa. While funding to renewable energy has been rising year on year, it is not leading to the change we would hope for. Presently, we are nowhere near on track to deliver on the SDG 7 goal of universal, affordable, modern and sustainable energy access for all. Far too much energy financing is still being directed to fossil fuels rather than renewable energy-most notably from commercial and investment banks. ${ }^{5}$ Development banks globally have in the last few years been reducing financing for fossil fuel projects from their portfolio, but most are yet to eliminate this despite it being directly contradictory to the emission reduction goals set in the Paris Agreement.

And data shows that despite claims of a green recovery approach in the wake of COVID-19's impact on development, a fifth ${ }^{6}$ of all financing deployed to the energy sector was directed towards fossil fuel projects since January 2020. The African Development Bank channeled a large chunk of energy funds (USD $254.09 \mathrm{~m}$ ) during this period to its Electricity and Green Growth programme (where the data is able to be quantified and/or disaggregated) but only USD $167.65 \mathrm{~m}$ towards clean energy projects ${ }^{7}$ despite the short- and long-term benefits of a COVID-19 recovery response that addresses energy access for health and livelihood impact, including but not limited to vaccine cooling and reducing household reliance on cost-ineffective and polluting cooking fuels, as well as food security, job creation and water access.

\section{Reaching those Left Behind}

Further, most of this funding-both prior to and post-pandemic - does not end up being directed towards decentralized renewable energy (DRE) or clean cooking projects. Instead, the focus remains on large scale infrastructure projects, which, while they can increase access to electricity,

\footnotetext{
${ }^{4}$ From https://www.seforall.org/news/seforall-global-tracking-frame work 'High-impact countries offer the most potential to make rapid progress towards the goals. Twenty high-impact countries in Asia and Africa account for about two-thirds those without access to electricity, and three-quarters of those who use solid fuels-wood, charcoal, animal and crop waste, and coal- to cook or heat their homes.'.

5 These are the world's largest banks that are increasing and decreasing their fossil fuel financing. https://www.cnbc.com/2021/04/22/ which-banks-are-increasing-decreasing-fossil-fuel-financing-.html.

${ }^{6}$ Fossil Finance from Multilateral Development Banks Reached USD 3 Billion in 2020, but Coal Excluded for the First Time Ever. https://www.iisd.org/articles/fossil-finance-multilateral-developmentbanks-reached-usd-3-billion-2020-coal-excluded.

7 Multilateral Development Banks Analysis. Analysis retrieved on 30 April 2021. https://www.energypolicytracker.org/institution_analysis/ mdbs/.
} 
and contribute to industrial development, also often end up furthering the gap between the 'have' and the 'have-nots'. DRE projects are effective because they are not only climate mitigating, but they can provide reliable access to electricity in communities that are geographically remote and typically marginalized in other ways-for instance due to national geopolitical factors or economic factors. These projects directly reach and change the economic trajectories of communities. But for a variety of reasons; DRE projects are not supported on as wide a scale as large-scale infrastructure projects. Globally, only 3\% of climate finance is directed towards DRE (Rai et al. 2016). Financiers have stated factors such as small ticket sizes, long loan tenures, and lack of capacity of either project implementers or (domestic) financiers themselves, but there needs to be more concerted efforts to work around these challenges and massively scale up financing for DREs. And the same must be done for clean cooking, especially when it comes to making modern cooking options accessible and affordable on a wide scale in African countries. Solutions such as aggregation of projects and blended finance approaches can go a long way towards contributing to this.

The pandemic also led to the number of people without electricity in Africa going up ${ }^{8}$ for the first time in 2020 after steady declines over the past few years. Similarly, regression in cooking fuel choices due to economic hardship have been observed, for instance in Kenya. ${ }^{9}$ Such a stark reversal shows that we need to do more to ensure that these advances in energy access are 'accessible, reliable and affordable'. And the time to act is now. African governments must think about support for renewable energy in their COVID responses, and support must come from other financing bodies. And while initial responses from the few African countries that crafted COVID-19 responses that addressed energy focused on the revenue generation and viability of power utilities, ${ }^{10}$ it is imperative that future responses focus on reaching those left behind. Africa must set pathways for achieving access to electricity and clean cooking through widespread implementation of DRE and clean cooking projects and programmes. This will include complementary steps such as creating strong policy and regulatory frameworks that include significant incentives for DRE and clean cooking projects, widespread consumer behavioural change campaigns, and close collaboration with the private sector, development partners and financiers to realize this change on a large scale.

\footnotetext{
8 The Covid-19 crisis is reversing progress on energy access in Africa. https://www.iea.org/articles/the-covid-19-crisis-is-reversingprogress-on-energy-access-in-africa.

9 Post Covid; reassessing access to clean cooking in low-income households. https://east-africa.hivos.org/opinion/post-covid-reassessing-access-to-clean-cooking-in-low-income-households/.

10 https://www.scidev.net/sub-saharan-africa/news/covid-19-renew able-energy-response-in-africa-meagre/
}

\section{Conclusion}

Climate change and energy usage are inextricably linked. Climate finance offers a great opportunity to link the two for effective solutions that will benefit local communities, particularly those that are rural and/or marginalized. But currently, only USD 1 of every 10 actually goes towards local climate action (Soanes et al. 2019). Because of the intermediaries and the lack of drive to create smaller, more locally responsive structures, just as in the fight for energy access, the current system of financing is not always reaching, or responsive to local communities' needs. There must be concerted efforts by the stakeholders with the financing and therefore the power to adjust their approaches. Financiers including development banks and multilateral organizations must develop devolved approach models that will enable them to funnel funds for both large-scale and smallscale projects effectively. National governments too, have a critical role to play in enabling this financing to reach communities through stimulating financing at local levels, creating and implementing supportive policy and regulatory frameworks and using their political will to demonstrate their commitment to supporting local action and communities. The creation of navigable financial mechanisms that will allow communities to co-create and implement their own local solutions for climate adaptation and mitigation is critical in the pathway to achieve our Paris Agreement emission reduction goals and simultaneously achieve universal access to clean energy.

\section{References}

Cabré, Miquel Muñoz, and Mohamed Youba Sokona. 2016. Renewable Energy Investment in Africa And Nationally Determined Contributions (NDCs). Global Economic Governance Initiative. https://www.bu.edu/pardeeschool/files/2016/11/RE-NDC-Africa_ Final.pdf.pdf.

Rai, Neha, Sarah Best, and Marek Soanes. (2016) Unlocking climate finance for decentralised energy access. London: IIED. http:// pubs.iied.org/16621IIED

Soanes, Marek, Clare Shakya, Anna Walnycki, and Sam Greene. 2019. Money where it matters: designing funds for the frontier. IIED Issue Paper. London: IIED. http://pubs.iied.org/10199IIED

Publisher's Note Springer Nature remains neutral with regard to jurisdictional claims in published maps and institutional affiliations. 